\title{
SOBRE NÚMEROS IRRACIONAIS E POSSIBILIDADES PARA SEU ENSINO
}

\author{
Bárbara Cristina Dâmaso de Jesus* \\ Viviane Cristina Almada de Oliveira**
}

\section{Resumo}

Este artigo tem como objetivo discutir os números irracionais como objeto de ensino na Educação Básica. Iniciamos essa discussão trazendo ao leitor questóes relacionadas à construção desse conjunto numérico ao longo dos tempos e partimos para elencar consideraçôes sobre o ensino dos irracionais sob a perspectiva de documentos oficiais e de vários autores envolvidos com essa temática. Buscamos, na escrita do texto, apresentar propostas de abordagem desses números que visem à produção de significados para um número irracional como um processo infinito que pode ser aproximado por um processo finito, estabelecendo assim outras relações entre as tradicionais abordagens via negação dos números racionais e via representação decimal.

Palavras-chave: Educação Matemática. Números irracionais. Produção de significados. Infinito. Aproximação.

\section{INTRODUÇÃo}

Números irracionais "são aqueles que possuem reticências no final". Assim um aluno do $1^{\circ}$ ano do Ensino Médio, no estudo dos conjuntos numéricos, referiu-se aos números irracionais em sala de aula. Essa afirmação indica o modo como um aluno nesse nível de ensino compreende esses números, o que nos sugere ser produtivo questionarmos sobre a abordagem dos números irracionais na Educação Básica.

Publicações na área de Educação Matemática apresentam discussões sobre algumas das dificuldades que alunos da Educação Básica geralmente têm na compreensão de ideias referentes aos irracionais. Distinguir um número racional e um número irracional passa, muitas vezes, pelo reconhecimento visual de certos padróes podendo, esse procedimento, levar a classificaçóes equivocadas desses números.

Santos (2007), em seu trabalho sobre o ensino de números reais na Educação Básica, apresenta alguns dos entraves à construção do conceito de número irracional. Destaca a identificação entre as representaçóes decimais $3,1416 \ldots$ e $\pi$ e também entre 2,7182... e e (número de Euler); a classificação de 3,1416... como sendo um número

Graduada em licenciatura Matemática pela Universidade Federal de São João del-Rei (UFSJ). Professora da Rede Estadual de Ensino de MG. E-mail: barbara-cris1012@hotmail.com

Doutora em Educação Matemática pela Universidade Estadual Paulista "Júlio de Mesquita Filho" - UNESP (Campus Rio Claro). Professora do Departamento de Matemática e Estatística da Universidade Federal de São João del-Rei (UFSJ). E-mail: viviane@ufsj.edu.br 
irracional; a confusão entre número e sua aproximação, atribuindo a ambos o mesmo significado; a definição de números irracionais como sendo somente aqueles representados com raízes; e o desconhecimento da existência de infinitos números irracionais.

Os Parâmetros Curriculares Nacionais (PCN) de Matemática para os anos finais do Ensino Fundamental consideram de suma importância que o ensino de qualquer temática seja significativo para o aluno, apontando que

[...] a aprendizagem em Matemática está ligada à compreensão, isto é, à atribuição e apreensão de significado; apreender o significado de um objeto ou acontecimento pressupóe identificar suas relaçóes com outros objetos e acontecimentos. [...] $\mathrm{O}$ significado da Matemática para o aluno resulta das conexôes que ele estabelece entre ela e as demais áreas, entre ela e os Temas Transversais, entre ela e o cotidiano e das conexóes que ele estabelece entre os diferentes temas matemáticos (BRASIL, 1998, p. 57).

Pensando nessas ideias, surgem algumas perguntas: Como podemos relacionar os números irracionais a outros objetos e acontecimentos? De que modo os números irracionais podem ser conectados a outras áreas, aos Temas Transversais, ao cotidiano e a outros temas matemáticos? Isso é possível?

$\mathrm{Na}$ sequência, apresentaremos algumas considerações acerca dos números irracionais, no que tange ao desenvolvimento histórico desses números, bem como ao ensino e à aprendizagem dessa temática no contexto escolar.

\section{SOBRE NÚMEROS IRRACIONAIS: AS IDEIAS DE IRRACIONALIDADE E INCOMENSURABILIDADE}

A Matemática desenvolvida pelos egípcios e babilônicos se caracterizava por sua aplicabilidade prática, isto é, vinculava-se às suas necessidades práticas do dia a dia e não à organização estrutural de uma ciência. Nesta época, algumas aplicaçôes práticas levaram estes povos a calcular aproximaçóes para $\pi$. Segundo Santos (2003, p. 1), babilônios e egípcios já sabiam que o perímetro do círculo poderia ser obtido multiplicando o seu diâmetro por essa constante. No entanto, embora percebida a existência de uma relação entre o diâmetro e o comprimento da circunferência, o que viria a ser a irracionalidade deste número só seria estabelecido posteriormente.

Já na Antiguidade, os gregos encaravam a Matemática como uma ciência propriamente dita, sem se preocupar com suas aplicaçóes, levando em conta problemas relacionados com processos infinitos, movimento e continuidade. A ideia de irracionalidade dos números irracionais nos remete aos Pitagóricos, durante o Período Helenístico (146 a.C. - 323 a.C.). Boyer descreve que, para os Pitagóricos, "a essência de tudo, na geometria como nas questôes práticas e teóricas da vida do homem, pode ser explicada em termos de arithmos, ou das propriedades intrínsecas dos inteiros e suas razôes" (BOYER, 2002, p. 50, grifo nosso). Tudo poderia ser medido a partir de uma unidade de medida. Assim, dois segmentos são comensuráveis quando "é possível expressar a medida de um deles utilizando o outro como unidade de medida" (MIGUEL, 2009, p. 219).

No entanto, não se sabe exatamente de qual circunstância teria surgido o problema da incomensurabilidade. Boyer (2002) supóe que tal fato pode ter ocorrido pela aplicação do Teorema de Pitágoras a um triângulo retângulo isósceles. Se considerarmos um quadrado de lado $l$ e diagonal $d$ e supusermos existir uma unidade $u$ tal que tanto $l$ quanto $d$ sejam escritos como múltiplos inteiros de $u$, poderemos afirmar existir uma fração irredutível $\frac{m}{n}$ tal que $d=\frac{m}{n}$. $l$. Sabendo que $d$ é a diagonal de um triângulo retângulo isósceles cujos catetos são $l$, deduz-se que $n$ é um número simultaneamente par e ímpar. Tal absurdo é obtido 
ao considerarmos que o lado $l=m \cdot u$ e a diagonal $d=m \cdot u$ são comensuráveis, em outras palavras, estamos considerando que $l$ e $d$ têm uma unidade de medida comum. Logo, $l$ e $d$ são incomensuráveis.

O estranhamento no caso do número irracional $\sqrt{2}$ aconteceu na tentativa de se calcular a medida da diagonal do quadrado de lado com medida igual a 1 , que recaía sobre o problema do triângulo retângulo isósceles. Sabia-se que a diagonal existia, pois era possível construí-la com régua e compasso; no entanto, não sabiam como definir e operar com esses novos números, havia lacunas na reta racional (EVES, 1997).

Há também grande possibilidade de a ideia de incomensurabilidade ter sido construída no processo de:

[...] simples observação de que quando se traçam as cinco diagonais de um pentágono, elas formam um pentágono regular menor e as diagonais do segundo pentágono por sua vez formam um terceiro pentágono regular, que é ainda menor. Esse processo pode ser continuado indefinidamente, resultando em pentágonos táo pequenos quanto se queira e levando à conclusão de que a razão da diagonal para o lado num pentágono regular não é racional (BOYER, 2002, p.50).

Com esta situação, surge a necessidade de desenvolver uma teoria sobre razóes envolvendo grandezas comensuráveis e incomensuráveis, uma vez que "o segmento já não podia mais ser considerado indivisível, mas infinitamente divisível" (BONGIOVANNI, 2005, p. 94).

Por outro lado, há autores que discordam deste drama na história dos irracionais. Grattan-Guinness, citado por Gonçalves e Possani, alega que

Outra descoberta famosa atribuída aos pitagóricos é usualmente formulada assim: $O$ número $\sqrt{2}$ é irracional; mas essa formulação é anacronística em vários modos. [...] a descoberta é tida como tendo provocado uma crise nos fundamentos da Matemática daquele tempo; mas comentadores como o próprio Aristóteles náo a mencionam, e a ideia pode ser uma interpolação anistórica de alguns gregos posteriores, ou mesmo um malentendido. [...] Assim, longe de experimentar uma crise de fundamentos, os gregos antigos podem ter gozado uma época de grandes jornadas matemáticas (GONÇALVES; POSSANI, 2009, p.7).

Roque (2012) também apresenta outra visão referente à história dos irracionais. Para ela, a Matemática abstrata e a teoria dos números, desenvolvida pelos pitagóricos, relacionada com a geometria, estavam em dois planos distintos. Isto é,

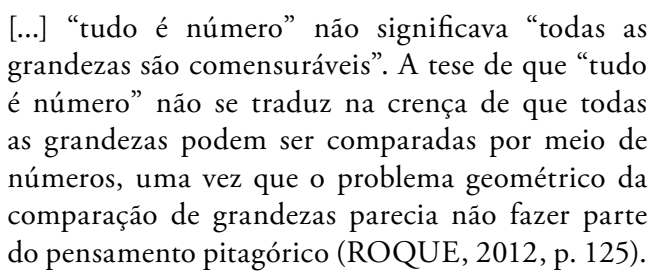

De todo modo, é possível observar que não é possível se estabelecer uma explicação única acerca das origens da ideia de irracionalidade. Entretanto, compreender tais possibilidades pode nos auxiliar na proposição de abordagens para o tratamento dos números irracionais em qualquer nível de ensino.

A proposta de solução para o problema da incomensurabilidade veio com Eudoxo (408 a 355 a.C.). A soluçâo se desenvolvia a partir do raciocínio geométrico e aritmético, com base no livro $\mathrm{V}$ (definição 6) ${ }^{1}$ dos Elementos, de Euclides. Segundo Bongiovanni (2005), Eudoxo desenvolveu uma teoria que envolvia os conceitos de grandezas comensuráveis e incomensuráveis, porém não os relacionou com a reta numérica. Considerou os segmentos $\mathrm{AD}, \mathrm{DB}, \mathrm{AE}$ e EC tais que $\frac{A D}{D B}=\frac{A E}{E C}$. Nessa configuração poderiam acontecer dois casos: os segmentos serem comensuráveis ou incomensuráveis.

Os gregos não tomaram o ente definido por essas classes, ou seja, o número real $\alpha$ que é a medida de um segmento em relação a outro segmento.

Em 1872, a exposição moderna de números irracionais dada pelo alemão J.W.R. Dedekind (1831 1916) coincide com as formulaçôes de Eudoxo. Segundo 
Bongiovanni (2005), Dedekind se questionou sobre o que existiria na grandeza geométrica que a distinguia dos números racionais e foi buscar inspiração nas teorias das proporções de Eudoxo.

No decorrer de seus estudos, Dedekind observou que:

\footnotetext{
1) Existe [sic] mais pontos na linha reta do que números racionais;

2) Então, o conjunto dos números racionais não

é adequado para aplicarmos aritmeticamente a continuidade da reta;

3) Logo, é absolutamente necessário criar novos números para que o domínio numérico seja tão completo quanto a reta, isto é, para que possua a mesma continuidade da reta (MIGUEL, 2009, p.233).
}

Com base nestas observações, o alemão Dedekind publicou em seu livro Stetigkeit und di Irrationalzahlen (Continuidade e Números Irracionais) a solução para o problema dos números irracionais através de operaçóes que chamou de cortes. Mol (2013) descreve que, para Dedekind, o conceito de limite deveria ser desenvolvido através da aritmética apenas, sem usar a geometria como guia. Perguntava-se o que havia na grandeza geométrica contínua que a distinguia dos números racionais. Chegou à conclusão de que a essência da continuidade de um segmento de reta náo se deve a uma propriedade de ligação mútua, mas a uma propriedade exatamente oposta: a natureza da divisão do segmento em duas partes por um ponto dado. Se os pontos de uma reta se dividem em duas classes tais que todos os pontos da primeira estáo à esquerda de todos os pontos da segunda, então existe um, e um só, ponto que realiza essa divisão em duas classes, isto é, que separa a reta em duas partes.

Dedekind observou que os teoremas fundamentais sobre limites podem ser demonstrados sem recorrer à geometria. De fato, foi a geometria que iniciou o caminho para uma definição de continuidade, mas, no fim, esta foi excluída da definição aritmética formal do conceito. Deste modo, a noção de corte de Dedekind, no sistema de números racionais, ou uma construção equivalente dos números reais, tinha agora substituído a grandeza geométrica como espinha dorsal da análise.

O que se pode observar é que, desde a primeira problematização sobre a ideia de irracionalidade na Grécia antiga até a definição atual de Dedekind, decorreu um longo espaço de tempo. $\mathrm{O}$ fato de a gênese que cerca a ideia de irracionalidade ter se prolongado durante tanto tempo pode ser indício da dificuldade de compreensão dos números irracionais no contexto escolar, o que nos aponta como importante nossa reflexão acerca do ensino desses números.

\section{ENSINO DE NÚMEROS IRRACIONAIS: EXPLORANDO E (RE)CONSTRUINDO CAMINHOS}

O longo período histórico que transcorreu na constituição da ideia de irracionalidade é indício de dificuldades que pensadores e estudiosos tiveram na sua compreensão. Atualmente, no contexto escolar, essa dificuldade parece se repetir no entendimento dos números irracionais. Pommer (2011, p. 2) afirma que, no campo de ensino da Matemática, os irracionais ainda permanecem como um problema e seu ensino demanda mais pesquisas e esclarecimentos.

Esse mesmo autor nos diz que "o conhecimento matemático dos Números Irracionais, adquirido através do movimento histórico e sistematizado pela comunidade de matemáticos, sofreu uma transposição didática para ser ensinado em sala de aula" (p. 21). Uma das dificuldades destacadas por Pommer para a compreensão dos números irracionais é o modo como se realiza a transposição didática desse tema. Geralmente, o conjunto dos números reais é tratado como a união de dois conjuntos disjuntos: os números racionais e os números irracionais; em seguida, o conjunto dos números irracionais é apresentado como sendo formado 
pelos números reais não racionais. Estabelece-se, assim, um quadro de circularidade. E, neste sentido, Pommer compreende ser necessário se repensar o ensino dos números irracionais em nível escolar.

A construção do conhecimento acerca dos números irracionais está diretamente relacionada com o conjunto dos números racionais e com sua ampliação. Moreira e David (2010) nos dizem que "[...] a noçâo do que seja número vem sendo ampliada desde a ideia básica do que seja número natural [...]” e, desse modo, “[...] o conjunto dos reais se apresenta para a comunidade escolar como uma construção cujo sentido é o de superar determinadas limitaçôes da noção anterior de número” (p. 80-81).

Outro problema recorrente no tratamento dos números irracionais é apontado por Bortolossi e Mózer. Esses autores consideram que um "erro frequente detectado entre os alunos é o de eles considerarem, por exemplo, que $\pi$ é igual a 3,14 e que $\sqrt{3}$ é igual a 1,73 ” (BORTOLOSSI; MÓZER, 2016, p. 3). Geralmente, considerações como essas, muitas vezes sugeridas pelo livro didático ou pelo professor, afastam a ideia da definição de número irracional do aluno. Este não compreende que 1,73 é uma aproximação com duas casas decimais de $\sqrt{3}$ e que, operando com essa aproximação, por exemplo, o resultado que será obtido ao final da operação também será uma aproximação.

A Base Nacional Comum Curricular (BNCC), documento de caráter normativo que define as chamadas aprendizagens essenciais que devem ocorrer na Educação Básica brasileira, foi instituída em dezembro de 2017 (BRASIL, 2017a); o prazo máximo para sua implementação pelas instituições de ensino, pela adequação de seus currículos à BNCC, é até o início do ano letivo de 2020. A BNCC apresenta como expectativa para os alunos dos anos finais do Ensino Fundamental que

(...) resolvam problemas com números naturais, inteiros e racionais, envolvendo as operaçóes fundamentais, com seus diferentes significados, e utilizando estratégias diversas, com compreensão dos processos neles envolvidos. Para que aprofundem a noçẫo de número, é importante colocá-los diante de problemas, sobretudo os geométricos, nos quais os números racionais não são suficientes para resolvê-los, de modo que eles reconheçam a necessidade de outros números: os irracionais (BRASIL, 2017b, p. 267).

Dentro da unidade temática Números, uma das cinco da área de Matemática, são determinados alguns objetos de conhecimento (entendidos como conteúdos, conceitos e processos) que devem ser vistos no $9^{\circ}$ ano do Ensino Fundamental; lá se encontram especificados: necessidade dos números reais para medir qualquer segmento de reta e números irracionais: reconhecimento e localização de alguns na reta numérica (BRASIL, 2017b, p. 314). As duas habilidades relacionadas a esses objetos de conhecimento são:

(EF09M A01) Reconhecer que, uma vez fixada uma unidade de comprimento, existem segmentos de reta cujo comprimento não é expresso nem por número racional (como as medidas de diagonais de um polígono e alturas de um triângulo, quando se toma a medida de cada lado como unidade).

(EF09M A02) Reconhecer um número irracional como um número real cuja representação decimal é infinita e não periódica, e estimar a localização de alguns deles na reta numérica (BRASIL, 2017b, p. 315).

Já o Conteúdo Básico Comum (CBC) de Matemática é o documento que, pelo menos até este ano, orienta a organizaçáo curricular no estado de Minas Gerais. A proposta curricular nele apresentada aponta conteúdos a serem tratados e habilidades que os alunos devem desenvolver a cada ano escolar, tanto para o Ensino Fundamental II quanto para o Ensino Médio.

No Ensino Fundamental II, a estruturação do CBC de Matemática se dá em quatro eixos temáticos (Números e Operações; Álgebra; Espaço e Forma; e Tratamentos de Dados) que possuem temas específicos da disciplina. Cada tema é dividido em tópicos, junto aos quais estão indicadas as respectivas habilidades a serem desenvolvidas pelos alunos por meio do seu estudo. 
Para os anos finais do Ensino Fundamental, o CBC de Matemática apresenta, dentro do Eixo Temático I - Números e Operações e inserido no Tema 1 - Conjuntos Numéricos, o tópico Conjunto dos números reais como sendo complementar, e não como obrigatório. As habilidades referentes a esse tópico são:

- Reconhecer a necessidade da ampliação do conjunto dos números racionais através de situações contextualizadas e da resolução de problemas.

- Identificar números racionais com as dízimas periódicas.

- Identificar as dízimas não periódicas com os números irracionais.

- Usar geometria para construir alguns segmentos de comprimento irracional (MINAS GERAIS, 2007, p. 22).

Para o Ensino Médio, o CBC de Matemática é organizado em três eixos temáticos distintos daqueles dos anos finais do Ensino Fundamental. São eles: I) Números, Contagem e Análise de Dados; II) Funçóes Elementares e Modelagem; e III) Geometria e Medidas. No eixo temático I é descrito, associado ao tema Números, o tópico Conjunto dos números reais. A ele está vinculado o desenvolvimento de duas habilidades específicas, que são: "Reconhecer uma dízima não periódica como uma representação de um número irracional. [...] Utilizar números racionais para obter aproximações de números irracionais" (MINAS GERAIS, 2007, p. 44).

Conforme essa orientação de distribuição dos tópicos, o conjunto dos números irracionais não é abordado nos $6^{\circ}$ e $7^{\circ}$ anos do Ensino Fundamental. Contudo, salientamos que ainda no $7^{0}$ ano já se pode trabalhar e discutir a ideia de infinito. Uma possibilidade bastante interessante, nessa direção, seria propor aos alunos realizarem divisões entre dois números naturais cujo resultado seja uma dízima periódica e observarem o comportamento do quociente durante o processo de divisão (BIANCHINI, 2011). Por exemplo, no processo de divisão de 11 por 7 (Figura 1), aparecerão, nesta ordem, os restos ${ }^{2} 4,5,1,3,2,6$; na continuação da divisão, aparecerá novamente o resto $4 \mathrm{e}$, na sequência, novamente os restos 5, 1, 3, 2 e 6 . Desse modo, ao se repetirem, sucessivamente, esses restos, o processo de divisão pode continuar acontecendo indefinidamente, o que leva ao surgimento no quociente do que chamamos de uma dízima periódica.

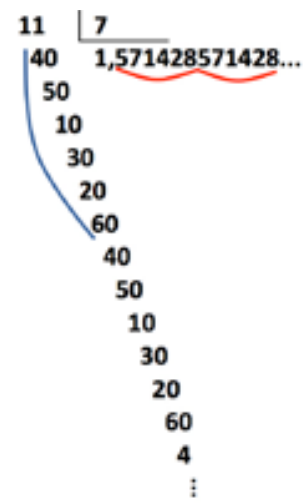

Figura 1 - Encontrando uma dízima periódica Fonte: as autoras

Este tipo de proposição é uma oportunidade para os alunos compreenderem a definição de período de uma dízima periódica e trabalhem com a ideia de infinito dentro de um processo que não tem fim.

O primeiro contato dos alunos com os números irracionais se dá no $8^{\circ}$ ano, conforme orientação do CBC, ou no $9^{\circ}$ ano, de acordo com a BNCC. Esse momento é "[...] certamente, muito difícil. Os números irracionais não existem no mundo concreto, são abstrações matemáticas, só existem no mundo das ideias, para aceitá-los é preciso imaginar processos infinitos e proximidades que tendem a zero" (GARCIA; FRONZA; SOARES, 2005, p. 6).

Concordamos com Pommer (2012) quando diz que "é importante discutir a questão de aproximação no ensino básico, podendo constituir poderoso meio de abordar os números irracionais, além de permitir 
esclarecer as conexóes com os números racionais" (POMMER, 2012, p. 39). Sendo assim, uma outra possibilidade de fazer essa discussão, dando início ao trabalho com os irracionais no $8^{\circ}$ ano, estaria relacionada à compreensão do que é a raiz quadrada de um número, juntamente com o uso da calculadora. Nessa etapa, na qual os alunos já tiveram contato com o cálculo de raízes quadradas de quadrados perfeitos, pode ser introduzido o cálculo do valor aproximado de raízes quadradas de números que não são quadrados perfeitos.

Por exemplo, pode-se calcular o valor aproximado da raiz quadrada do número 23 , convidando os alunos a observar o que acontece nesse processo. Como 23 está compreendido entre 16 e 25 , podemos dizer que $16<23<25$. Assim, a raiz quadrada de 23 estará compreendida entre $\sqrt{16}$ e $\sqrt{25}$, ou seja, $4<\sqrt{23}<5$. $\mathrm{O}$ uso da calculadora pode ser interessante a partir do momento em que tomarmos um valor $m_{1}$ compreendido entre 4 e 5 e encontramos seu quadrado, observando se é superior ou inferior a 23. Se inferior, estabelecem-se as desigualdades $m_{1}<\sqrt{23}<5$; se superior, estabelecem-se as desigualdades $4<\sqrt{23}<m_{1}$. Se o valor de $m_{1}$ tomado for tal que $m_{1}<\sqrt{23}<5$, considera-se um novo valor $m_{2}$, compreendido entre $m_{1}$ e 5 , calcula-se o quadrado de $m_{2}$; sendo ele inferior ou superior a 23 , determinamse, respectivamente, novas desigualdades: ou $m_{2}<\sqrt{23}$ $<5$ ou $m_{1}<\sqrt{23}<m_{2}$. Se o valor de $m_{1}$ tomado for tal que $4<\sqrt{23}<m_{l}$, considera-se um novo valor $m_{2}$, compreendido entre 4 e $m_{l}$, calcula-se o quadrado de $m_{2}$; sendo ele inferior ou superior a 23 , determinam-se, respectivamente, novas desigualdades: ou $m_{2}<\sqrt{23}<m_{1}$ ou $4<\sqrt{23}<m_{2}$. Dando sequência a esse procedimento, encontramos números que se aproximam cada vez mais de $\sqrt{23}$.

Essa proposta de abordagem, além de permitir uma discussão sobre aproximação, é uma oportunidade para o professor retomar com seus alunos questóes relacionadas a números decimais vistas em anos escolares anteriores e, principalmente, para abordar a noçáo de infinito. Juntas, as noçóes de infinito e de aproximação são importantes para preparar os alunos para o trabalho com os números irracionais.

A dificuldade com esses números inicia-se na sua introdução. Geralmente, os números irracionais são apresentados aos alunos como os números não racionais, números que não podem ser escritos como a razão de dois números inteiros, ou então como os números com infinitas casas decimais não periódicas. Moreira e David (2010) chamam a atenção para esse fato argumentando que:

\footnotetext{
Ora, se o universo numérico dos alunos ainda é o conjunto dos racionais, nenhuma dessas duas caracterizaçóes tem qualquer significado. Quanto não se sabe o que significa uma forma decimal infinita e não periódica também não se sabe o que é um número irracional e vice-versa. Do mesmo modo, se a ideia escolar de número está associada, na sua acepção mais ampla, apenas a uma razão de inteiros, os irracionais não são números já que não são razão de inteiros. [...] No final, define-se o conjunto dos números reais como a uniáo dos racionais com os irracionais. Fecha-se, assim, um ciclo de inconsistências, e náo se esclarece o sentido de se conceber os irracionais como números ou o significado que possa vir a ter essa nova espécie de número (MOREIRA; DAVID, 2010, p. 82).
}

Retomando o quadro de circularidade na definição do conjunto dos números reais, Garcia, Fronza e Soares acreditam que apresentar os irracionais, alegando não serem eles números racionais, pode deixar dúvidas sobre a existência dos irracionais. Indicam ainda que "não se faz relação entre as questóes geométricas que originaram a criação dos irracionais com este conteúdo. Inverte-se a ordem, colocando-se a Geometria depois dos Irracionais" (GARCIA; FRONZA; SOARES, 2005, p. 16).

Geralmente, as abordagens de representações de números na reta real se limitam apenas aos conjuntos dos inteiros e dos racionais, reforçando uma visão 
equivocada de que a reta numérica é formada apenas por esses últimos números. Abordar a representação dos números irracionais na reta numérica por construçóes geométricas (Figura 2) - o que é importante para a compreensão desse conjunto numérico e também dos números reais - exige do professor enfatizar junto aos

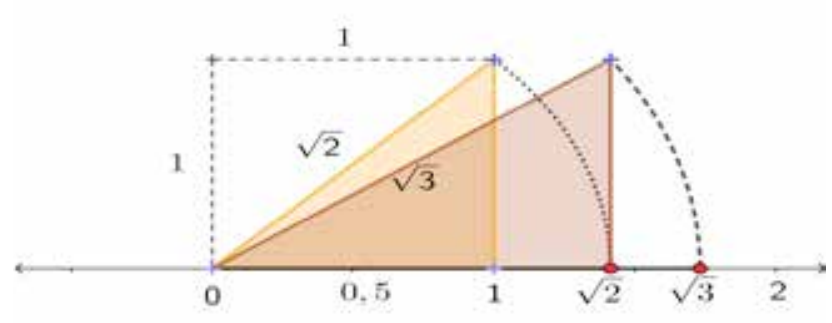

Figura 2 - Representação dos números irracionais Fonte: as autoras

Para tanto, um encaminhamento possível em sala de aula seria, por exemplo, propor aos alunos a construçáo de retângulos (Figura 3) - dadas as medidas racionais de seus lados - nos quais as medidas dos segmentos das diagonais obtidas sejam números irracionais. Em situaçóes como essa, entendemos valer a pena explorar com os alunos tanto o processo algébrico envolvido no cálculo da medida da diagonal do retângulo quanto, especificamente, utilizando-se uma régua graduada e considerando-se a unidade de medida tomada para a construção dos lados do retângulo, a medição dessa diagonal. Muitas vezes, a possibilidade de se tomar uma medida - que é aproximada - da diagonal do retângulo, representando-a com um número decimal, pode causar um estranhamento (LINS, 2004) com relação ao fato de, algebricamente, a medida obtida ser um número irracional. Criar em sala de aula um momento de discussão que relacione as medidas obtidas algébrica e manualmente pode ser profícuo para que seja problematizada essa relaçáo entre número irracional e sua aproximação racional. alunos que muitas dessas representaçóes se constituem em uma localização aproximada. Entretanto, no caso de números que são a medida das diagonais de um retângulo, esse comprimento é tão preciso e tão exato quanto os comprimentos dos lados do quadrilátero (MOREIRA; FERREIRA, 2012).

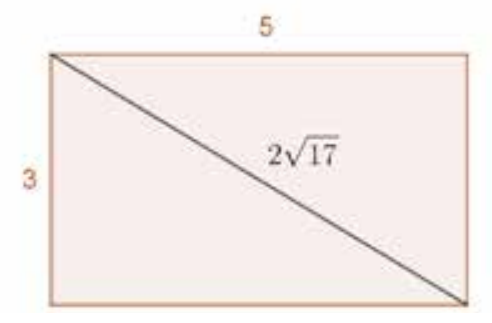

Figura 3 - Retângulo cuja diagonal é irracional $\sqrt{2}$ e $\sqrt{3}$ na reta numérica

Fonte: as autoras

No tratamento das operações que envolvem radicais - adição, subtração, multiplicação, divisão, que acontece a partir dos anos finais do Ensino Fundamental -, nota-se determinada preocupação com os cálculos, muitas vezes deixando de lado a compreensão dos números racionais e irracionais com os quais se opera. A partir da introduçâo dos números irracionais, Pommer (2012) nos indica que, frequentemente, os livros didáticos restringem sua abordagem "[...] ao cálculo aproximado e a [sic] representação geométrica, não destacando a problemática do significado relativo ao conceito de aproximação, nem colocam em evidência a questão conceitual da incomensurabilidade" (POMMER, 2012, p. 117).

Um dos números irracionais estudados por alunos em vários momentos da Educação Básica, cujo tratamento segue esse caminho, é o número $\pi$. Em pesquisa realizada por Bortoletto, sobre as abordagens do ensino do número $\pi$, esse autor nos diz que

[...] a maioria dos professores que introduzem $\pi$ na $5^{\text {a }}$ série não o definem como "número irracional" 
e sim como "número resultante de uma razão" e quanto aos professores que ensinam $\pi$ a partir da $7^{\mathrm{a}}$ série, a maioria o define como "número irracional" (BORTOLETTO, 2008, p.59).

Esta maneira de conduzir o estudo do $\pi$ primeiramente como número resultante da razão entre o comprimento da circunferência e seu raio e, depois, como um número irracional - pode induzir o aluno a considerar que o $\pi$ pode ser escrito como a razão de dois números inteiros. Enfatizamos aqui a pertinência de que, neste contexto de tratamento dos números irracionais, sejam discutidas operaçóes envolvendo tais números, de modo a criar oportunidades para que o aluno compreenda que, se a razão de dois números resulta em um número irracional, como é o caso do $\pi$, é porque pelo menos um desses números é irracional.

Outra ocasião em que, na Educação Básica, os estudantes se deparam com o número $\pi$ é no estudo da Trigonometria. $\mathrm{O}$ trabalho que frequentemente se exige dos alunos, muitas vezes mecânico, de conversão de medidas de ângulos dadas em radianos para graus pode sugestionar ao aluno considerar $\pi$ como sendo $180^{\circ}$, já que um ângulo de $\pi$ radianos equivale a um ângulo de $180^{\circ}$. Dessa maneira, pode-se assim estabelecer para o número p uma compreensão que se contrapõe à definição de um número irracional. Acreditamos que, se não discutido em sala de aula o processo de conversão entre essas unidades de medidas, o qual passa pela definição da unidade de medida radiano e pela consideração do comprimento da circunferência como sendo $2 \pi R$ (onde $\mathrm{R}$ é o raio da circunferência), considerar o número $\pi$ como $180^{\circ}$ é algo bastante possível de ocorrer.

\section{CONSIDERAÇóES FINAIS}

Ao longo da história, verifica-se a existência de diversos relatos sobre o desenvolvimento da ideia de irracionalidade, desde o "choque" dos pitagóricos com números que não podiam ser mensurados até a noção de cortes de Dedekind. Com base nessas histórias, é possível perceber a dificuldade da humanidade em produzir e, ao mesmo tempo, compreender as ideias envolvidas com os números irracionais.

De certo modo, similarmente à(s) história(s) desses números, no ensino dos números irracionais também é possível identificar dificuldades no entendimento e na compreensão das suas ideias por alunos da Educação Básica. Alguns autores acreditam que esta dificuldade está relacionada com o modo com que se realiza a transposição didática do tema. Esta dificuldade na transposição já pode ser identificada na definição dos conjuntos numéricos. Por isso a necessidade de se repensar o ensino dos números irracionais no âmbito escolar.

No repensar esse ensino, percebemos o desenvolvimento das ideias de aproximação e de infinito como fundamentais para que o aluno compreenda os conceitos e as operaçóes relacionados à irracionalidade. Essas ideias podem ser (re)tratadas e (re)discutidas antes mesmo da introdução formal do conteúdo números irracionais e, acreditamos, (re)tratadas e (re)discutidas em outros momentos e contextos posteriores à tal introdução.

Perspectivas distintas enriquecem abordagens dos números irracionais que podem ser promovidas. $(\mathrm{Re})$ criar situaçóes próximas às que podem ter se sucedido historicamente e para ela produzir significados (LINS, 1999; 2004) nos parece uma abordagem possível e didaticamente interessante. Outros elementos importantes, nem sempre considerados nas discussóes sobre números irracionais, são recursos como a régua graduada e a calculadora como auxiliares no desenvolvimento das ideias de infinito e aproximação.

Nesta perspectiva, é crucial a criticidade do professor de Matemática ao utilizar o livro didático que adotar, de modo que possa complementar e alterar as propostas nele oferecidas, buscando promover situaçóes que favoreçam a aprendizagem do aluno no que se refere aos números irracionais. 
O que observamos, a partir das consideraçóes feitas acerca dos números irracionais, é que seu ensino envolve ideias que, para serem compreendidas, demandam do professor de Matemática implementar em sala de aulas práticas educativas que se configurem como oportunidades para os alunos discuti-las, problematizálas e estranhá-las. Mais uma vez, destacamos dentre elas as ideias de infinito e de aproximação. Sendo criadas tais oportunidades, acreditamos que, ao final da Educação Básica, seja possível que adolescentes e jovens produzam significados para números irracionais na direção apontada por Pommer, de que "[...] tais expressóes [dos números irracionais] representam um processo infinito, que pode ser aproximado por um processo finito, expressando assim resultados da operação de aproximação, na concepção de que esta pode ser melhorada o quanto se deseje ou se necessite" (POMMER, 2012, p. 164).

\section{ON IRRATIONAL NUMBERS AND POSSIBILITIES FOR THEIR TEACHING}

\section{Abstract}

This article aims to discuss the Irrational Numbers as an object of instruction in Basic Education. We begin this discussion by bringing to the reader questions related to the construction of this numerical set over time and then we list considerations about the teaching on irrational numbers from the perspective of official documents and various authors involved with this theme. We propose to present proposals to approach these numbers that aim at the production of meanings for an irrational number as an infinite process that can be approximated by a finite process, thus establishing other relations between the traditional approaches through the denial of rational numbers and via decimal representation.
Keywords: Mathematics Education. Irrational Numbers. Meanings production. Infinite. Approximation.

\section{SObRE NÚMEROS IRRACIONALES Y POSIBILIDADES PARA SU ENSEÑANZA}

\section{Resumen}

Este artículo tiene como objetivo discutir los Números Irracionales como objeto de enseñanza en la Educación Básica. Hemos empezado esta discusión trayendo al lector las cuestiones relacionadas con la construcción de este conjunto numérico a lo largo de los siglos y comenzando con consideraciones acerca de la enseñanza de los irracionales bajo la perspectiva de los documentos oficiales y varios autores involucrados con este tema. Buscamos en la escritura del texto presentar propuestas de abordaje de esos números que apunten a la producción de significados para un número irracional como un proceso infinito que puede ser aproximado por un proceso finito, estableciendo así otras relaciones entre los tradicionales enfoques mediante la negación de los números racionales y mediante representación decimal.

Palabras clave: Educación Matemática. Números Irracionales. Producción de significados. El infinito. Aproximación.

\section{Notas}

Diz-se que quatro grandezas estáo na mesma razáo, a primeira para a segunda e a terceira para quarta, se, quando equimúltiplos quaisquer são tomados da primeira e da terceira e equimúltiplos quaisquer, da segunda e da quarta, os primeiros equimúltiplos são ambos maiores que, ou ambos iguais a, ou ambos menores que, os últimos equimúltiplos considerados em ordem correspondentes (BONGIOVANNI, 2005, p. 96).

Importante ressaltar que, no processo de divisão, no caso de uma divisão por um número $\mathrm{k}$, natural não nulo, haverá, no máximo, (k-1) restos distintos. 


\section{REFERÊNCIAS}

BIANCHINI, E. Matemática Bianchini. 7. ed. São Paulo: Editora Moderna. 2011.

BONGIOVANNI, V. As duas maiores contribuiçôes de Eudoxo Cnido: a teoria das proporçóes e o método de exaustão. UNIÓN - Revista Iberoamericana de Educación Matemática. n.2, p.91-110. jun. 2005.

BORTOLETTO, A. R. S. Reflexóes relativas às definições do número $\pi$ (pi) e à presença da sua história em livros didáticos de matemática do ensino fundamental. 2008. p. 139. Dissertação (Programa de Pós-graduação em Educação). Faculdade de Ciências Humanas da Universidade Metodista de Piracicaba, 2008.

BORTOLOSSI, H. J.; MÓZER, G. S. Para que servem os Números Irracionais? Indo além das fórmulas de perímetros, áreas e volumes. In: Encontro Nacional de Educação Matemática, 12, 2016, São Paulo. Anais. 2016.

BOYER, C. B. História da matemática. Editora Edgar Blücher. 2. ed. São Paulo. 2002

BRASIL. Secretaria de Educação Fundamental. Parâmetros Curriculares Nacionais: Matemática. Brasília, 1998.

BRASIL. Ministério da Educação. Resolução no 2, de 22 de dezembro de 2017a. Disponível em < http://basenacionalcomum.mec.gov.br/wpcontent/uploads/2018/04/RESOLUCAOCNE_ CP222DEDEZEMBRODE2017.pdf. > Acesso em: 06 mar. 2018.

BRASIL. Ministério da Educação. Base Nacional Comum Curricular. Brasília: MEC, 2017b.

EVES, H. Introdução à história da matemática. 2. ed. Campinas, SP: Unicamp,1997.

GARCIA, V. C. FRONZA, J. SORES, D.S. Ensino dos números irracionais e reais no ensino fundamental: coleção cadernos para professores. Porto Alegre: Universidade Federal do Rio Grande do Sul, 2005. v.1

GONÇALVES C. H. B., POSSANI C. Revisitando a descoberta dos incomensuráveis na Grécia Antiga. Matemática Universitária, v.47, p.16-24. 2009.

LINS, R. C. Por que discutir teoria do conhecimento é relevante para a educação matemática. In: BICUDO, M.
A. V. (Org.). Pesquisa em educação matemática: concepçóes e perspectivas. Rio Claro: Editora Unesp, 1999. p. 75-94.

LINS, R. C. Matemática, monstros, significados e educação matemática. In: LINS, R. C. Educação Matemática: pesquisa em movimento. São Paulo: Cortez, 2004. p.92-120.

MIGUEL, A... [et al.]. História da matemática em atividades didáticas. 2. ed. rev. São Paulo: Editora Livraria da Física, 2009.

MINAS GERAIS. Conteúdos Básicos Comuns - CBC Matemática - Ensino Fundamental e Médio: proposta curricular. Secretaria do Estado da Educação. Belo Horizonte, MG, 2007.

MOL, Rogério Santos. Introdução à história da matemática. Belo Horizonte. Universidade Federal de Minas Gerais CAED. 2013. Disponível em: < http://www.mat.ufmg.br/ ead/acervo/livros/introducao_a_historia_da_matematica. pdf.> Acesso em: 20 fev. 2018.

MOREIRA, P. C.; DAVID, M. M. M. S. A formação matemática do professor: licenciatura e prática docente escolar. Belo Horizonte: Autêntica Editora, 2010. 120 p. (Coleção Tendências em Educação Matemática, 11).

MOREIRA, P. C.; FERREIRA, M. C. C. O que é número real? Os números reais na formaçáo do professor da Educação Básica. In: Cury, H. N.; Vianna, C. R. (Orgs.). Formação do professor de matemática: reflexóes e propostas. Santa Cruz do Sul: Editora IPR, 2012. p. 49-94.

POMMER, W. M. Números irracionais no ensino fundamental: uma análise em livros didáticos. Encontro Paraense de Educação Matemática. Belém, PA. 2011. Disponível em: < http://stoa.usp.br/wmpommer/files/3812/20209/CO+2011 +EPANEM+Livro+Did\%C3\%A1tico.pdf >. Acesso em: 15 abr. 2017.

POMMER, W. M. A construçâo de significados dos números irracionais no ensino básico: uma proposta de abordagem envolvendo os eixos constituintes dos Números Reais. 2012. p. 235. Tese (Doutorado em Educação) - Faculdade de Educação, Universidade de São Paulo, São Paulo, 2012.

ROQUE, T. História da matemática: uma visão crítica, desfazendo mitos e lendas. Rio de Janeiro: Zahar, 2012.

SANTOS, J. C. Números reais: um desafio na Educação Básica. 2007. Disponível em: < http://www.meusiteantigo. uff.br/wmrezende/uploads/Monografia_Real.pdf >. Acesso em: 21 nov. 2017. 
SANTOS, J. C. S. O. Uma breve história de $\pi$. Gazeta de Matemática, n. 145, p.43-48, jul. 2003. Disponível em: < http://gazeta.spm.pt/getArtigo?gid=80 >. Acesso em: 11 abr. 2017.

Enviado em 30 de maio de 2018. Aprovado em 13 de julho de 2018. 